\title{
Increased cerebral blood flow in the right frontal lobe area during sleep precedes self-awakening in humans
}

Sayaka Aritake ${ }^{1,2,3,4^{*}}$, Shigekazu Higuchi ${ }^{1,5}$, Hiroyuki Suzuki ${ }^{1}$, Kenichi Kuriyama ${ }^{6}$, Minori Enomoto ${ }^{1,4}$, Takahiro Soshi ${ }^{6}$, Shingo Kitamura ${ }^{1}$, Akiko Hida ${ }^{1}$ and Kazuo Mishima ${ }^{1}$

\begin{abstract}
Background: Some people can subconsciously wake up naturally (self-awakening) at a desired/planned time without external time stimuli. However, the underlying mechanism regulating this ability remains to be elucidated. This study sought to examine the relationship between hemodynamic changes in oxyhemoglobin (oxy-Hb) level in the prefrontal cortex and sleep structures during sleep in subjects instructed to self-awaken.

Results: Fifteen healthy right-handed male volunteers with regular sleep habits participated in a consecutive two-night crossover study. The subjects were instructed to wake up at a specified time ("request" condition) or instructed to sleep until the morning but forced to wake up at 03:00 without prior notice ("surprise" condition). Those who awoke within \pm 30 min of the planned waking time were defined as those who succeeded in self-awakening ("success" group). Seven subjects succeeded in self-awakening and eight failed.

No significant differences were observed in the amounts of sleep in each stage between conditions or between groups. On the "request" night, an increase in oxy-Hb level in the right prefrontal cortex and a decrease in $\delta$ power were observed in the "success" group around 30 min before self-awakening, whereas no such changes were observed in the "failure" group. On the "surprise" night, no significant changes were observed in oxy-Hb level or $\delta$ power in either group.
\end{abstract}

Conclusions: These findings demonstrate a correlation between self-awakening and a pre-awakening increase in hemodynamic activation in the right prefrontal cortex, suggesting the structure's contribution to time estimation ability.

Keywords: Time estimation ability, Self-awakening, Sleep, Cognitive science, Prefrontal cortex, Insomnia

\section{Background}

We are often able to wake up spontaneously at a desired or planned time or to subconsciously estimate time elapsed during sleep without receiving external time stimuli such as from an alarm clock. This phenomenon is referred to as self-awakening [1-5] or anticipated sleep termination [6], and it is believed to be achieved by time estimation ability (TEA) [7], which is exercised even during sleep $[8,9]$. A previous study reported that more than half of healthy adults believe that they are able to

\footnotetext{
* Correspondence: sayaca@tokyo-med.ac.jp

'Department of Psychophysiology, National Institute of Mental Health, National Center of Neurology and Psychiatry, Tokyo 187-8502, Japan 2Japan Society for the Promotion of Science, Tokyo 102-8471, Japan Full list of author information is available at the end of the article
}

wake up by themselves during habitual sleep with an accuracy (i.e., difference between planned and actual wake up time) of $\pm 10 \mathrm{~min}$ [10].

Previous studies have identified several factors related to TEA during sleep, including an increased adrenocorticotropic hormone $(\mathrm{ACTH})$ level observed before awakening [6], recurrent semi-awakening during sleep [11,12], differences in preceding sleep structures [13,14], diurnal fluctuation [15,16], and psychological motivation $[3,17]$. However, the brain region responsible for TEA has not been identified. Meanwhile, considerable information has been obtained regarding the neurological basis of TEA while awake [18-21]. The basal nuclei (corpus striatum), cerebellum, and prefrontal cortex have been shown to

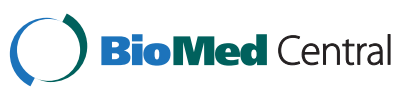


contribute to TEA in the order of seconds to minutes, and each of these three regions plays a different role. The cerebellum processes mainly timing information [22-24], the basal nuclei, in particular the corpus striatum, functions as a core timer [25-27], and the prefrontal cortex assists the basal nuclei in controlling timer rate, attention allocation, and temporal memory processing [26,28-30]. Despite the possible contributions of these brain regions and the interval timer system to TEA during sleep, no study has continuously monitored the activity of these regions during the course of natural sleep. Thus, the neurological basis of TEA during sleep remains to be elucidated.

Several recent studies have shown changes in cerebral hemodynamics during sleep with near infrared spectroscopy (NIRS) [31-35]. One study showed a decrease in oxy-Hb levels of $5-10 \%$ from baseline (before sleep onset) during the first $60 \mathrm{~min}$ of sleep [32,33]. This technique has the potential to elucidate specific hemodynamic change during self-awakening. The objective of this study was to determine whether the prefrontal cortex mediates self-awakening by: 1) setting two night conditions ("request", where subjects were instructed at bedtime to wake up $3 \mathrm{~h}$ after lights out, earlier than the regular wake time; and "surprise", where subjects were instructed to sleep for $8 \mathrm{~h}$ after lights out but forced to wake up $3 \mathrm{~h}$ after lights out without prior notice); and 2) measuring hemodynamic changes to the prefrontal cortex over time by multi-channel NIRS while simultaneously measuring sleep structures by polysomnography (PSG) during the first $3 \mathrm{~h}$ after lights out.

\section{Methods \\ Participants}

Fifteen healthy, right-handed male volunteers (age $22.1 \pm$ 0.7 years (mean $\pm \mathrm{SD})$ ) with regular sleep habits participated in the consecutive two-night, single-blind, crossover conditions ("request" and "surprise"). All subjects provided written informed consent after being informed of the possible risks and details of the study. A physician and a psychiatrist examined the subjects and found that no subjects suffered from a neurological or psychiatric disorder or had a history of psychoactive drug use. Subjects were instructed to maintain a regular sleep-wake schedule, record their sleep patterns in a sleep log, and abstain from caffeine, nicotine, and alcohol for 1 week prior to the experiment. All subjects wore a wrist activity recorder (Actiwatch-L, Mini-Mitter Co., Inc. Bend, OR) for 1 week prior to the experiment. Sleep onset and offset times were determined using Actiware Sleep software (V3. 2 MiniMitter Co., Inc.). Data recorded in the sleep logs together with sleep onset and offset times were used to confirm regular sleep-wake schedules. The study protocol was approved by the Ethics Committee of the Institutional
Review Board of the National Center of Neurology and Psychiatry, Japan.

\section{Experimental procedures}

All experiments were performed in the time isolation laboratory at the National Center of Neurology and Psychiatry in Japan. Room temperature and humidity were controlled at $24^{\circ} \mathrm{C}$ and $60 \%$, respectively. Subjects arrived at the sleep laboratory at 21:00 and were instructed to go to bed at 00:00 (Lights off) after electrodes and sensors for PSG and NIRS were attached. Each subject was randomly allocated to the "request" or "surprise" sessions on a within-subject crossover basis as follows: 1) "request": subjects were instructed at bedtime to wake up at 03:00; and 2) "surprise": subjects were instructed at bedtime to wake up at 08:00, but were unexpectedly woken at 03:00 (Figure 1). When a subject could self-awaken at 03:00 \pm $30 \mathrm{~min}$, the event was recorded as "success". When a subject could not awaken spontaneously at 03:00 $\pm 30 \mathrm{~min}$, the event was recorded as "failure". Each subject was examined under the other condition the following night.

\section{Measurement}

Simultaneous measurement of PSG and NIRS was performed throughout the sleep period, which was defined as the period from sleep onset to the designated wake time defined for each condition. PSG comprised electroencephalography (EEG; Fp1-A2, Fp2-A1, F3-A2, F4-A2, C3-A2, C4-A1, O1-A2, and O2-A1) in accordance with the 10-20 electrode system, electrooculography (EOG; left-A2 and right-A1), chin surface electromyography (chin-EMG), and electrocardiography (ECG). PSG data were obtained continuously during each experiment, digitalized at $500 \mathrm{~Hz}$, and stored in a digital EEG system (Comet, Grass Technologies, Astro-Med, Inc., RI). The high cut and low cut filters were set at $60 \mathrm{~Hz}$ (except chin-EMG at $120 \mathrm{~Hz}$ ) and $0.5 \mathrm{~Hz}$, respectively.

NIRS of the human brain is a relatively flexible technique for measuring hemodynamic changes on the basis of differences in the absorbance of harmless nearinfrared light between oxyhemoglobin (oxy-Hb) and deoxyhemoglobin (deoxy-Hb), and NIRS has been used to elucidate the physiological mechanisms of the blood oxygen level-dependent response [36-42]. Previous studies showed that NIRS signals correlate strongly with functional magnetic resonance imaging (fMRI) measurements [42,43].

In our study, regional hemodynamic changes in brain tissue were monitored using a continuous wave-type fNIRS system (OMM-3000, Shimadzu Corporation, Kyoto, Japan), which consisted of three semiconductor laser diodes producing wavelengths of 780, 805, and $830 \mathrm{~nm}$. This system is used to calculate changes in oxy$\mathrm{Hb}$, deoxy- $\mathrm{Hb}$, and total-Hb levels on the basis of the 


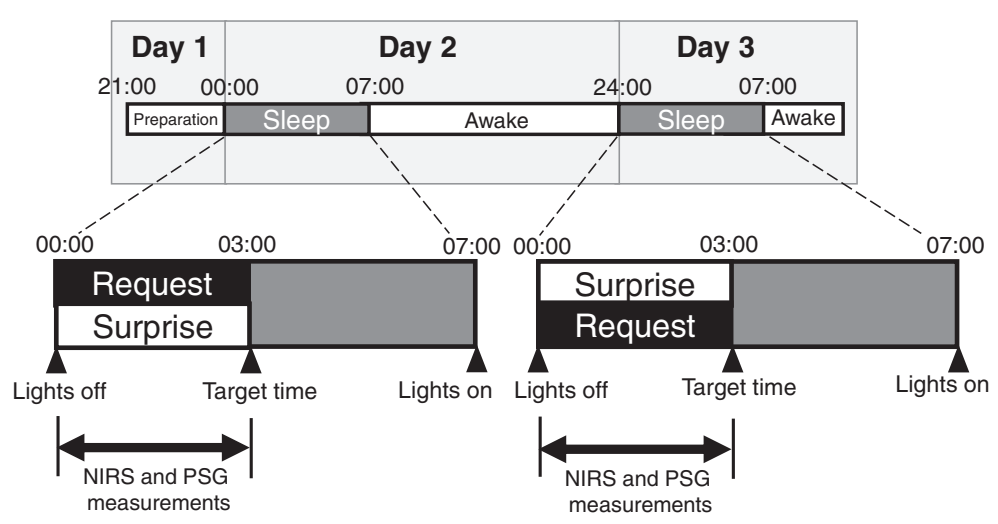

Figure 1 Experimental schedule. Subjects arrived at the sleep laboratory around 21:00 and were instructed to go to bed at 00:00 (lights off) after preperations were made to measure PSG and NIRS. Experiments under each of the two conditions were conducted twice for each subject in a consecutive two-night, single-blind crossover setting ("request" and "surprise") without notice of which condition would be examined first. Each subject was randomly allocated to one of two conditions and instructed at bedtime to wake up at: 1) 03:00 ("request"); or 2) 08:00, but was unexpectedly woken at 03:00 ("surprise"). When the subject could self-awaken at 03:00 \pm 30 min, the result was recorded as "success" or otherwise as "failure". Each subject was examined under the other condition the following day.

modified Beer-Lambert equation as a function of light absorbance of $\mathrm{Hb}$ and pathlength $[44,45]$. Since the used wavelengths are in a relatively narrow range, their corresponding pathlengths are assumed to be approximate to those of the algorithm used in the OM-3000 system. Thus, changes in oxy- $\mathrm{Hb}$ levels were calculated using changes in absorption ( $\Delta$ abs) and the absorption coefficient of each wavelength, but without the differential pathlength factor (DPF) for adjustment $[46,47]$. The relevant equations are as follows:

$$
\begin{aligned}
\Delta \text { oxy }-\mathrm{Hb}= & (-1.4887) \times \Delta \mathrm{abs}[780 \mathrm{~nm}] \\
+ & 0.5970 \times \Delta \mathrm{abs}[805 \mathrm{~nm}] \\
+ & 1.4847 \times \Delta \mathrm{abs}[830 \mathrm{~nm}] \\
\Delta \text { deoxy }-\mathrm{Hb}= & 1.8545 \times \Delta \mathrm{abs}[780 \mathrm{~nm}] \\
& +(-0.2394) \times \Delta \mathrm{abs}[805 \mathrm{~nm}] \\
& +(-1.0947) \times \Delta \mathrm{abs}[830 \mathrm{~nm}] \\
\Delta \text { total }-\mathrm{Hb}= & \Delta \text { oxy }-\mathrm{Hb}+\Delta \text { deoxy }-\mathrm{Hb}
\end{aligned}
$$

The coefficients in equations (1), (2), and (3) are coefficients of absorption at corresponding wavelengths. Determining changes in $\mathrm{Hb}$ levels with the modified Beer-Lambert Law depends on DPF, but optical pathlengths differ among individuals and depend on the position within the brain. Thus, oxy-Hb values measured by the OMM-3000 system show relative change in concentration, as opposed to absolute $\mathrm{Hb}$ concentration.

Optrodes for producing near-infrared light $(\mathrm{n}=10)$ and for collecting transmitted light $(\mathrm{n}=10)$ were placed alternately at $3-\mathrm{cm}$ intervals in a $4 \times 5-\mathrm{cm}$ square on the frontal cortex (FC) area (Fpz, Fz, C3, and C4 were used to adjust the position of the optrodes), resulting in 31 channels for measuring each $\mathrm{Hb}$ level every $200 \mathrm{~ms}$
(Figure 2). The energy emitted by each laser diode during long-term exposure was well below the United States safety level (Class $1 \mathrm{M}$ ) [48]. Subject behavioral status and sleep-wake status, as well as hemodynamic status, were continuously and carefully monitored visually by two well-trained research attendants. In our study subjects, we confirmed the following: 1) oxy-Hb levels were stable for at least $10 \mathrm{~min}$ before lights-off on the

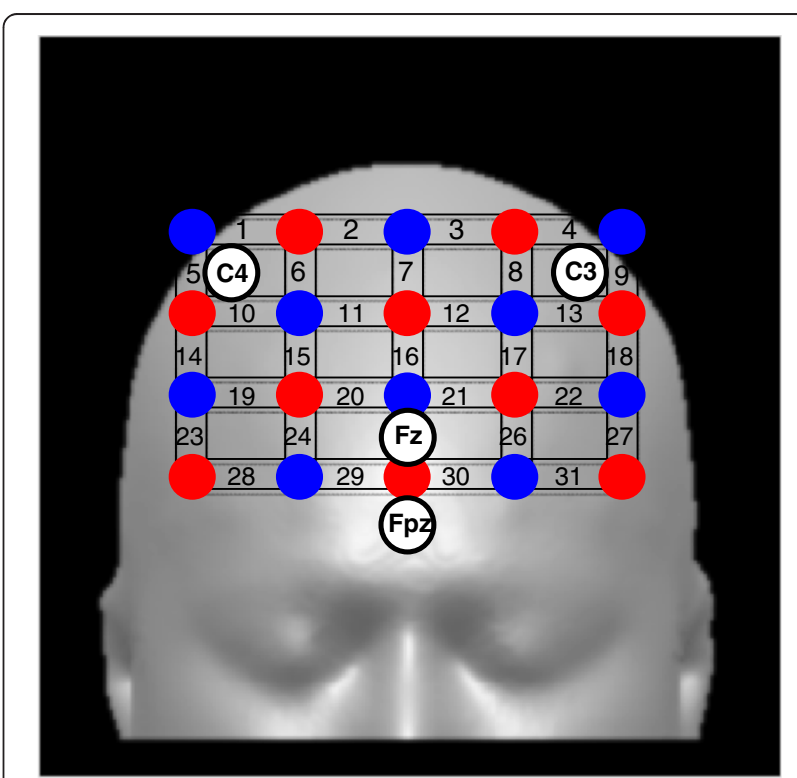

Figure 2 Approximate positions of the $\mathbf{3 1}$ fNIRS channels superimposed on a head model. The 31 measuring channels were produced by optrodes placed equidistantly over the prefrontal cortex (PFC) area. The lower line of the $4 \times 5$ optrode probe was positioned along the reference curve linking C3, C4, FZ, and FPz. Red denotes source optrodes and blue denotes detector optrodes. 
experimental night in a recumbent position on the bed; and 2) subjects showed decreased oxy-Hb levels of 5-10\% from baseline (before sleep onset) during the first $60 \mathrm{~min}$ of sleep, which is consistent with findings in previous studies [32,33].

\section{Data analysis}

NIRS data could not be obtained from 4 of 15 subjects due to displacement of light-producing optrodes during sleep. Evaluation of sleep structures was made for 15 subjects while analysis of sleep structures in relation to oxy-Hb was performed for the 11 subjects with available NIRS data.

PSG data obtained over a period of about $3 \mathrm{~h}$ were scored for 30-s epoch periods according to standard criteria [49]. The amount of stage $\mathrm{W}$, stage 1 , stage 2 , stage $3+4$, and stage REM sleep, as well as sleep latency, wake after sleep onset (WASO), and arousal index [35,50] for total sleep time were calculated for all PSG recordings. Slow-wave sleep was calculated as the sum of stage 3 and stage 4 sleep. The frequency of body movement during sleep was determined by viewing a monitor and EEG waveforms in real-time. For more detailed analysis of sleep structures, power spectral analysis using fast Fourier transform (FFT) as a parameter of brain activity at the cortical level was also examined with Sleep Sign (Kissei Comtec, Nagano, Japan). The EEG power (delta: 0.5-4 Hz; theta: 4-8 Hz; alpha: 8-13 Hz, and sigma: 13-15 Hz) of F3-A2 and F4-A1 was obtained by FFT analysis of 2048 data-points $(8 \times 4.096-s$ sequences $)$ tapered by a Hanning window. Since the eight sequences are longer than the visual epoch definitions for sleep staging, both sides of each sequence overlapped by $0.39 \mathrm{~s}$. FFT values for each sequence were summed to obtain the value of EEG power per epoch. Epochs containing artifacts were visually identified and excluded from the analysis.

We focused on changes of oxy-Hb in the 60- to 30-min period before self-awakening, since previous study demonstrated increases in adrenocorticotropic hormone levels during this period [6]. NIRS analysis on the "request" night was performed using data obtained from each subject during the final $30 \mathrm{~min}$ before self-awakening. On the "surprise" night, data obtained during the same period as that on the "request" night were used for analysis. NIRS data obtained from multiple analyzable channels every $200 \mathrm{~ms}$ were averaged every $30 \mathrm{~s}$ in line with PSG analysis to calculate $\mathrm{Hb}$ levels after excluding visible artifacts. A $0.02-1 \mathrm{~Hz}$ band pass filter was applied to individual data to remove artifacts caused by high-frequency instrument noise and low-frequency drift in oxy- $\mathrm{Hb}$ and deoxy- $\mathrm{Hb}$ signals in the fNIRS system. Since oxy-Hb level determined by NIRS is the most sensitive and representative optimal indicator of regional hemodynamic changes, we used this parameter in our analysis [32,36,51]. For the analysis of each right and left FC (rPFC and IPFC) region, we averaged the channels separately for each side (right and left) and region (rPFC region: 14, 15, 19, 20, 23, 24, 28, and 29; and IPFC region: 17, 18, $21,22,26,27,30$, and 31).

\section{Statistical analysis}

To determine the effect of the order of each experimental condition on sleep duration during each PSG period, we compared the nocturnal duration of each sleep stage between the groups under each experimental condition using two-way measures ANOVA. We also analyzed the rate of oxy- $\mathrm{Hb}$ changes between the groups under the each experimental condition using two-way ANOVA (experimental condition $\times$ group). To compare fluctuations in oxy-Hb levels, individual sleep structures, and EEG power with time between the groups under each experimental condition, three-way (1 between-subjects factor and 2 within-subjects factors) repeated measures ANOVA (experimental condition $\times$ results group $\times$ time course) was performed. If significant interactions were obtained, planned follow-up ANOVA and post-hoc analysis were subsequently conducted to verify our assumption that changes in hemodynamics and EEG power in the prefrontal cortex area mediates self-awakening. SPSS ver. 18.0 (IBM, Cary, NC) was used for all statistical analysis. Results are expressed as mean and standard error values. Significance was set at $p<0.05$.

\section{Results}

\section{Self-awakening success and failure}

In this study, 7 of 15 subjects succeeded in waking up at the predetermined time (03:00) under the "request" condition.

\section{Sleep structures}

Table 1 shows sleep parameters for the full sleep period (3 h) after lights-out until self-awakening or forced awakening and the final 30 min before waking in the 15 subjects by condition ("request" vs. "surprise") and group ("success" vs. "failure"). Two-way ANOVA (experimental condition $\times$ group) revealed no significant differences in any of these parameters for any of the sleep periods or between the groups or conditions.

\section{Thirty minutes before waking}

\section{Temporal changes in oxy-Hb levels in the PFC region}

Figure 3 shows the change in oxy-Hb level during the 30-min period before waking in one "success" and one "failure" subject. The upper panel shows that the oxy-Hb level in the rPFC area of the "success" subject gradually increased under the "request" condition, but not under the "surprise" condition (Figure 3A). In contrast, in the 
Table 1 Sleep structures over $3 \mathrm{~h}$ and final $30 \mathrm{~min}$

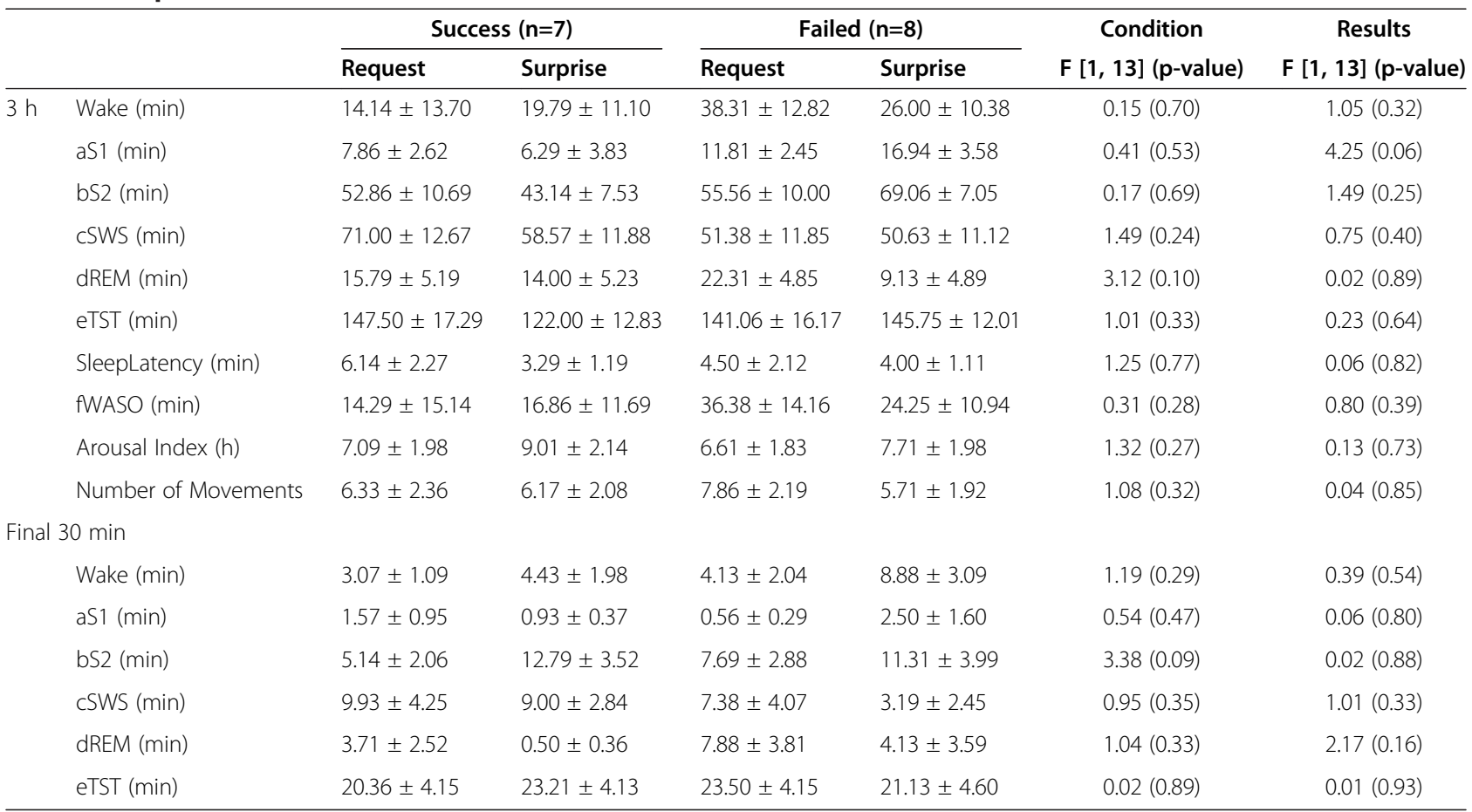

Request: experimental condition where subjects were instructed at bedtime to wake up at 03:00.

Surprise: experimental condition where subjects were instructed at bedtime to wake up at 08:00, but were unexpectedly woken at 03:00.

Success: when a subject could self-awaken at 03:00 $\pm 30 \mathrm{~min}$.

Failure: when a subject could not awaken spontaneously at 03:00 $\pm 30 \mathrm{~min}$.

${ }^{a}$ stage 1 sleep; ${ }^{b}$ S2: stage 2 sleep; cSWS: stage $3+4$ sleep; ${ }^{d}$ REM: stage rapid eye movement sleep; ${ }^{e}$ TST: total sleep time; ${ }^{f}$ WASO: wake after sleep onset. ${ }^{*}$ p < 0.05.

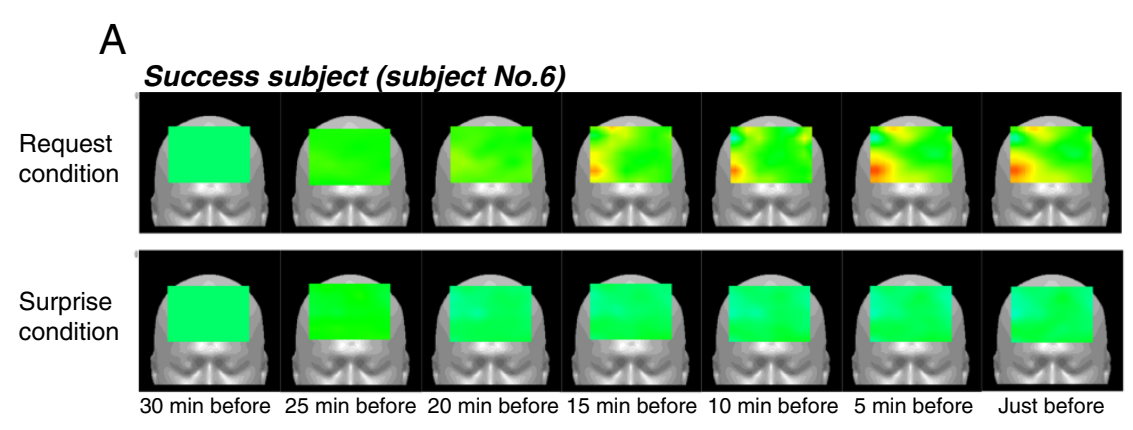

B

Failure subject (subject No.15)

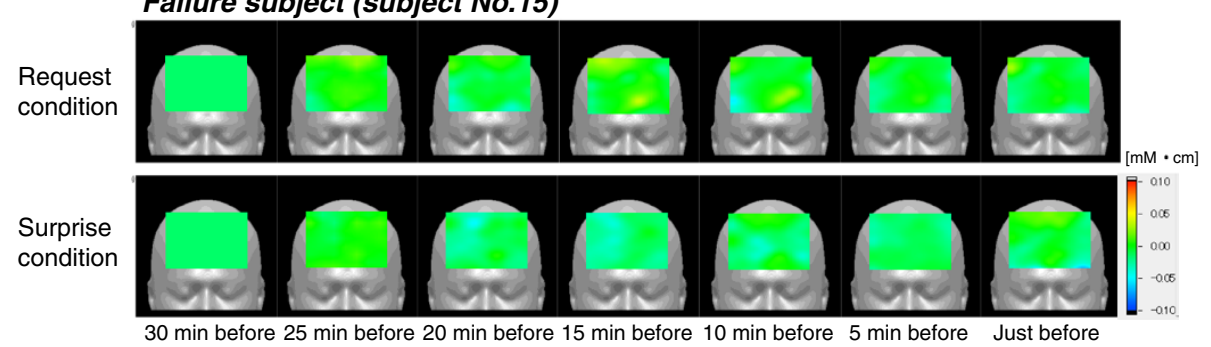

Figure 3 Change of oxy-Hb level during $\mathbf{3 0}$ min before waking in one "success" and one "failure" subject. Upper panel shows the gradual increase in oxy-Hb level in the right prefrontal region of a "success" group subject on the "request" night but not on the "surprise" night (A). In contrast, the oxy-Hb level showed no increase under either condition in the "failure" subject (B). 
"failure" subject, the oxy-Hb level showed no increase under either condition (Figure 3B).

Figure 4A shows changes in oxy-Hb levels in the rPFC and IPFC area of 11 subjects during the final $30 \mathrm{~min}$ of sleep under each condition. In the rPFC area, three-way ANOVA (condition $\times$ time course $\times$ group) showed a significant second-order interaction (condition $\times$ time course $\times$ group: $\left.F_{(6,54)}=2.813, \quad \mathrm{p}=0.019\right)$. Planned follow-up two-way repeated ANOVA (time course $\times$ group) revealed that the oxy-Hb level under the "request" condition increased gradually $20 \mathrm{~min}$ before predominant waking in the "success" group compared with the "failure" group, and a significant interaction of time course $\times$ group was observed $\left(F_{(6,54)}=3.345, \mathrm{p}=0.007\right)$. Additional follow-up one-way ANOVA revealed that oxy- $\mathrm{Hb}$ level increased significantly with time in the "success" group $\left(F_{(5,54)}=7.238, p=0.016\right)$, but not in the "failure" group $\left(F_{(5,54}=2.154, p=0.113\right)$. The post-hoc test confirmed a significant difference between groups at 5 min before predominant waking (Bonferroni, $\mathrm{p}=0.001$ ) (Figure 4A-1). Under the "surprise" condition, follow-up two-way ANOVA revealed that fluctuation of oxy-Hb levels did not differ with time between the "success" and "failure" groups (interaction: $F_{(1,9)}=0.801, p=0.574$; time course: $F_{(6,54)}=1.675, p=0.145$; group: $F_{(1,9)}=$ $1.200, p=0.302$ ) (Figure 4A-3). In the lPFC area, oxy$\mathrm{Hb}$ level did not show any significant differences (condition: $F_{(1,9)}=1.226, p=0.297$; time course: $F_{(6,54)}$ $=2.225, p=0.098$; group: $\left.F_{(1,9)}=0.102, p=0.757\right)$ nor an interactions $\left(F_{(6,54)}=1.556, p=0.178\right)$ (Figure 4A-2, A-4).

For oxy-Hb changes over $30 \mathrm{~min}$ in the rPFC area, a significant interaction of condition $\times$ group was obtained $\left(F_{(1,9)}=3.513, p=0.034\right)$ (Figure 4B-1, B-3). Under the "request" condition, the additional post-hoc test revealed

\section{Request condition}

Right frontal cortex region

\section{Left frontal cortex region}

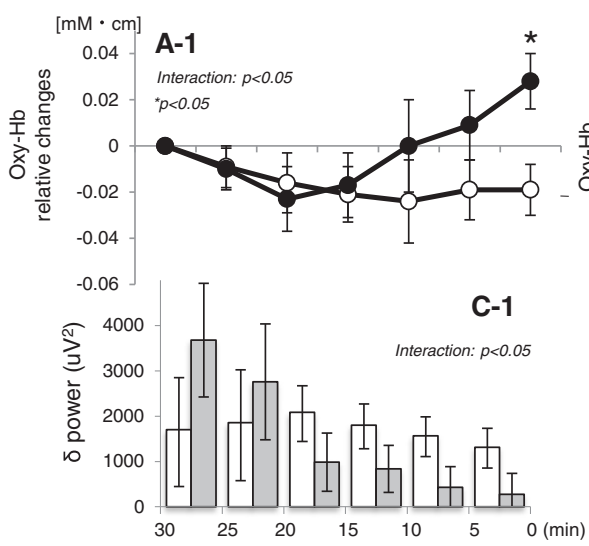

A-2

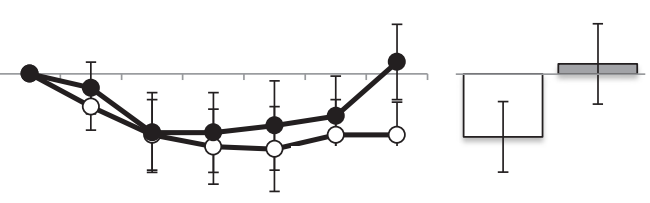

$-0.06$

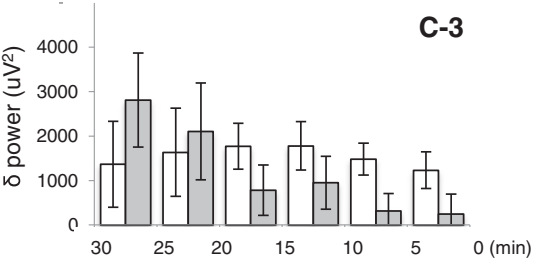

\section{Surprise condition}
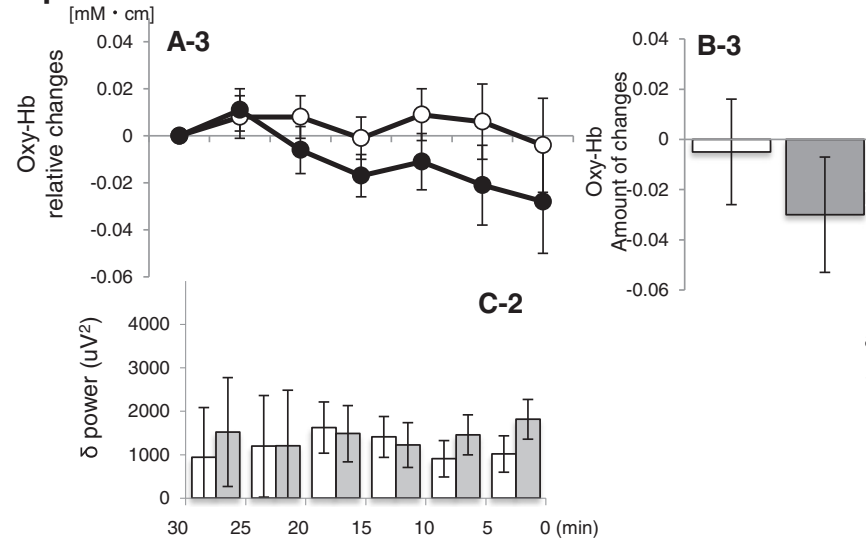

A-4
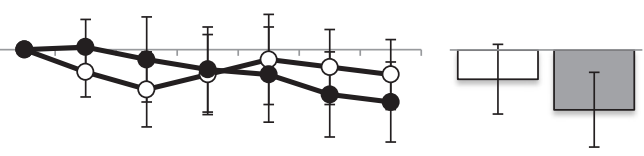

C-4

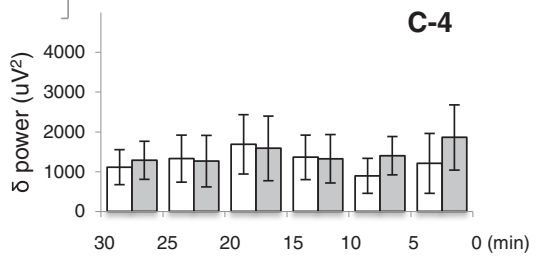

Figure 4 Change of oxy- $\mathrm{Hb}$ level and sleep structures during the final $\mathbf{3 0}$ min before waking $(\mathbf{n}=\mathbf{1 1})$. Temporal change in the oxy-Hb level $(\mathbf{A})$, the rate of oxy-Hb levels (B), and temporal change $\delta$ power in the prefrontal cortex (PFC) region (C) during the final 30 min before waking in 11 subjects. The "request" condition and oxy-Hb level (change according to time course and the rate during the final 30 min before waking) in the right PFC ( $\mathrm{rPFC}$ ) region gradually increased 20 min before predominant waking in the "success" group (black circle) compared with the "failure" group (O) (A-1, B-1). The delta power of the "success" group also decreased in the rPFC region with time under the request condition (C-1). 
that the rate of oxy-Hb change in the "success" group increased significantly more than in the "failure" group $\left(F_{(1,9)}=7.768, p=0.021\right)$, but not under the "surprise" condition $\left(F_{(1,9)}=0.668, p=0.435\right)$. Meanwhile, in the IPFC area, no difference in oxy-Hb change was observed (condition: $F_{(1,9)}=0.275, p=0.021$; group: $F_{(1,9)}=0.287, p=$ 0.605 ; interaction: $F_{(1,9)}=2.183, p=0.174$ ) (Figure 4B-2, B-4).

\section{Temporal changes in sleep structures}

Two-way ANOVA revealed a significant interaction of time course $\times$ group under the "request" condition (interaction: $F_{(5,45)}=3.037, p=0.019$; time course: $F_{(5,45)}=0.494, p=$ 0.779; group: $\left.F_{(1,9)}=1.833, p=0.209\right)$, but not under the "surprise" condition (interaction: $F_{(5,45)}=1.134$, $p=0.356$; time course: $F_{(5,45)}=0.867, p=0.511$; group: $\left.F_{(1,9)}=0.902, p=0.367\right)$. Moreover, additional one-way ANOVA confirmed a significant increase in REM stage sleep in the "success" group with time under the "request" condition (time course: $F_{(5,45)}=2.739, p=0.043$ ). Fluctuations of values in other sleep stages did not differ between condition or group.

\section{Temporal changes in $\delta$ power}

Figure 4-C shows changes in $\delta$ power in the IPFC and rPFC area during the final $30 \mathrm{~min}$ of sleep under each condition. In the rPFC region, three-way ANOVA showed a significant interaction of time course $\times$ group $\left(F_{(5,45)}=3.426, \quad p=0.010\right)$. Follow-up one-way ANOVA revealed that $\delta$ power decreased significantly with time in the "success" group $\left(F_{(5,45)}=3.113, p=0.031\right)$, but not in the "failure" group $\left(F_{(5,45)}=0.485, p=\right.$ 0.784 ) (Figure $4 \mathrm{C}-1, \mathrm{C}-3$ ). In the $\mathrm{PFC}$ region, threeway ANOVA showed no significant difference with time between conditions and groups (condition: $F_{(1,45)}=$ $0.001, p=0.972$; time course: $F_{(1,45)}=1.739, p=0.145$; group: $\left.F_{(5,45)}=0.014, p=0.908\right)$ or interaction $(\mathrm{p} \geq 0.05$ for all) (Figure 4C-2, C-4).

\section{Discussion}

We examined changes in oxy-Hb levels during sleep as well as sleep depth and amount over time until a planned wake time under the "request" and "surprise" conditions by simultaneously recording NIRS and PSG data. The results revealed that under the "request" condition, an increase in the oxy-Hb level in the right prefrontal region and a rapid decrease in $\delta$ power occurred during the final $30 \mathrm{~min}$ of sleep in subjects who succeeded in self-awakening, whereas no changes were observed in these three parameters in subjects who failed to self-awaken. Under the "surprise" night condition, no significant changes were observed in these parameters during the final 30 min of sleep in either group.

\section{Success rate for self-awakening}

Seven of the 15 subjects succeeded in self-awakening. A previous telephone survey involving 300 subjects showed that more than half of the subjects were able to wake up naturally without an alarm clock [3]. Hall and Brush tested whether subjects could wake up at a predetermined time on 50-100 nights and reported that about $70 \%$ were able to wake up almost exactly at the planned time $[52,53]$. The self-awakening success rate in the present study is almost identical to that in previous studies.

\section{Sleep structures preceding self-awakening}

Although the neurological mechanism mediating selfawakening has not been clarified, it has been postulated that strong motivation toward self-awakening and resulting psychological strain reduces slow-wave sleep and increases shallow sleep, resulting in a lowered arousal threshold [54]. Previous studies of sleep structures preceding self-awakening have yielded discrepant results; some showed a decrease in sleep depth $[1,54]$, while others showed no change [6]. In the present study, assessment of sleep structures over the entire period between lights out and self-awakening showed no significant difference between the "request" and "surprise" nights. Meanwhile, the analysis results of sleep structures immediately before self-awakening and those of power analysis had several important implications. First, it should be noted that subjects who succeeded in selfawakening showed an increase in REM sleep over time during the final $30 \mathrm{~min}$ of sleep on the "request" night. However, the total amount of REM sleep during the period did not differ between conditions, and no such increase was observed in subjects who failed. Since REM sleep tends to occur at around $3 \mathrm{~h}$ after lights out-in other words, at the planned wake time-it is not surprising that REM sleep occurred during the final $30 \mathrm{~min}$ before self-awakening. Nevertheless, the fact that increased REM sleep was observed just before self-awakening in the "success" group under the "request" condition, but not under the "surprise" condition, supports the contention that increased REM sleep facilitates successful selfawakening $[10,13]$. Second, it should be noted that a rapid decrease in $\delta$ power was also observed in the same area during the final $30 \mathrm{~min}$ of sleep in the "success" group under the "request" condition. This suggests that the rapid decrease in $\delta$ power around the planned time of self-awakening and the associated reciprocal increase in REM sleep may contribute to successful self-awakening.

\section{Mechanism and localization of self-awakening}

Subjects who succeeded in self-awakening showed an increase in oxy- $\mathrm{Hb}$ level in the right prefrontal region before self-awakening on the "request" night, which 
appears to reflect increased blood flow in the region. However, no significant differences were seen between groups for frequency of body movement, duration of each sleep stage, WASO, or total sleep time during the same period. It is thus unlikely that the observed increase in oxy-Hb level before self-awakening was caused by a change in the oxy-Hb level in association with coarse fluctuation of sleep structures or body movement. Subjects who succeeded in self-awakening showed decreased $\delta$ power and increased REM sleep during the final $30 \mathrm{~min}$ of sleep on the "request" night. It is likely that these changes in sleep structures secondarily or simultaneously led to a change in local blood flow in the prefrontal region [55]. It is therefore reasonable to assume that increased blood flow in the prefrontal region resulted in self-awakening and the consequent arousal reaction. However, it remains unclear in our study why the blood flow increased significantly in the right but not the left prefrontal region.

It has been suggested that self-awakening is achieved by some kind of drive related to time recognition during sleep [8]. The present findings support this contention indirectly. At least in the awake state, the basal nuclei (corpus striatum), cerebellum, and right prefrontal region have been shown to contribute to TEA [24,26,27]. The right prefrontal region, in which increased oxy-Hb levels were observed, is a region that showed increased blood flow in awake subjects during a time recognition test $[30,56]$, suggesting the contribution of increased blood flow in this region to successful self-awakening. However, the kind of physiological factors that trigger the increase in REM sleep or blood flow in the right prefrontal region during the $30 \mathrm{~min}$ before awakening in the present study remain unclear. Born et al. observed an increased ACTH level about $1 \mathrm{~h}$ prior to anticipated sleep termination [6]. Positron emission tomography (PET) studies that have examined the correlation between cerebral blood flow, ACTH, and cortisol levels while awake have demonstrated that increased secretion of ACTH and cortisol correlates with increased blood flow [57-60]. Subjects in the present study who succeeded in self-awakening might also have had increased the activity of the hypothalamic-pituitary-adrenal axis before self-awakening.

The present findings suggest the involvement of preawake activation of the right prefrontal region in selfawakening. The effect of heart rate and peripheral vasodilation on cerebral blood flow is important when interpreting the present data. Such factors are expected to have various effects on the measured responses under different conditions ("request" versus "surprise") and in different groups ("success" versus "failure"). Therefore, it is likely that heart rate and peripheral vasodilation played specific roles in the "success" group under the "request" condition. In addition, the sample population was relatively small, due to highly complex procedures involving spontaneous PSG and NIRS over the period of $3 \mathrm{~h}$ during sleep. Findings of this study need to be confirmed by other methods such as PET and fMRI. Once confirmed, further studies using techniques such as simultaneous measurement of fMRI and sleep EEG are needed to determine whether the deep brain regions, which are considered to be related to TEA and include the basal nuclei (striatum) and cerebellum, are involved in achieving self-awakening. Moreover, it will be necessary to elucidate whether TEA in the order of hours during sleep occurs in the same manner as TEA in the order of seconds to minutes. From the clinical viewpoint, patients who repeatedly experience sleep state misperception/paradoxical insomnia [61-63], waking after sleep onset, or waking in the early morning may have excessive and persistent activation of the right prefrontal region, which is caused by undefined mechanisms during sleep. Thus, elucidation of the neural mechanism of self-awakening should contribute to elucidating the pathophysiology of such difficult-to-treat insomnia symptoms.

\section{Conclusions}

Our present findings demonstrate a correlation between self-awakening and a pre-awakening increase in hemodynamic activation in the right prefrontal cortex, suggesting the structure's contribution to time estimation ability.

\section{Competing interests}

The authors declare that they have no competing interests.

\section{Authors' contributions}

SA and KM conceived the study. SA performed the experiments and the statistical analysis and participated in drafting the manuscript. $\mathrm{SH}, \mathrm{HS}, \mathrm{KK}, \mathrm{ME}$, TS, YA, SK, and AH performed the experiments. SA, HS, KK, and TS participated in study design and its coordination. KM helped with formulating the study hypotheses and drafting of the manuscript. All authors read and approved the final manuscript.

\section{Acknowledgements}

We thank Masao Inoue for help with the NIRS analysis. We also thank Yujiro Taguchi and Sayaka Kohtoh for help with the FFT analysis. This study was supported in part by the Strategic Research Program for Brain Sciences from the Ministry of Education, Culture, Sports, Science and Technology of Japan (Understanding of molecular and environmental bases for brain health) and the Research Grant for Nervous and Mental Disorders (11-3), a Health Science Grant (15130301) from the Ministry of Health, Labor and Welfare of Japan, a Grant-in-aid for Scientific Research (19790185). All authors declare no conflicts of interest associated with this study.

\section{Author details}

${ }^{1}$ Department of Psychophysiology, National Institute of Mental Health National Center of Neurology and Psychiatry, Tokyo 187-8502, Japan. 'Japan Society for the Promotion of Science, Tokyo 102-8471, Japan. ${ }^{3}$ Department of Somnology, Tokyo Medical University, Tokyo 160-0023, Japan. ${ }^{4}$ Department of Life Sciences and Bio-informatics, Graduate School of Allied Health Sciences, Tokyo Medical and Dental University, Tokyo 113-0034, Japan. ${ }^{5}$ Department of Human Science, Faculty of Design, Kyushu University, Fukuoka 815-8540, Japan. 'Department of Adult Mental Health, National 
Institute of Mental Health, National Center of Neurology and Psychiatry, Tokyo 187-8502, Japan.

Received: 30 September 2012 Accepted: 11 December 2012 Published: 21 December 2012

\section{References}

1. Zung WW, Wilson WP: Time estimation during sleep. Biol Psychiatry 1971, 3:159-164.

2. Webb WB, Ross W: Estimation of the passing of four consecutive hours. Percept Mot Skills 1972, 35:768-770.

3. Moorcroft WH, Kayser KH, Griggs AJ: Subjective and objective confirmation of the ability to self-awaken at a self-predetermined time without using external means. Sleep 1997, 20:40-45.

4. Kaida K, Nakano E, Nittono H, Hayashi M, Hori T: The effects of selfawakening on heart rate activity in a short afternoon nap. Clin Neurophysiol 2003, 114:1896-1901.

5. Ikeda $H$, Hayashi M: The effect of self-awakening from nocturnal sleep on sleep inertia. Biol Psychol 2010, 83:15-19.

6. Born J, Hansen K, Marshall L, Molle M, Fehm HL: Timing the end of nocturnal sleep. Nature 1999, 397:29-30.

7. Tang NK, Harvey AG: Time estimation ability and distorted perception of sleep in insomnia. Behav Sleep Med 2005, 3:134-150.

8. Bell C: Awakening from sleep at a pre-set time. Percept Mot Skills 1980, 50:503-508.

9. Aritake-Okada S, Uchiyama M, Suzuki H, Tagaya H, Kuriyama K, Matsuura M, Takahashi K, Higuchi S, Mishima K: Time estimation during sleep relates to the amount of slow wave sleep in humans. Neurosci Res 2009, 63:115-121.

10. Zepelin H: REM sleep and the timing of self-awakenings. Bull Psychomonic Soc 1986, 24:254-256.

11. Kleitman N: Sleep and Wakefullness. Chicago \& London: The University of Chicago Press; 1963:122-126.

12. Tart CT: Waking from sleep at a preselected time. J Am Soc Psychosom Dent Med 1970, 17:3-16.

13. Lavie P, Oksenberg A, Zomer J: It's time, you must wake up now. Percept Mot Skills 1979, 49:447-450.

14. Aritake $\mathrm{S}$, Uchiyama M, Tagaya $H$, Suzuki $H$, Kuriyama K, Ozaki A, Tan X, Shibui K, Kamei Y, Okubo Y, Takahashi K: Time estimation during nocturnal sleep in human subjects. Neurosci Res 2004, 49:387-393.

15. Spati J, Munch M, Blatter K, Knoblauch V, Jones LA, Cajochen C: Impact of age, sleep pressure and circadian phase on time-of-day estimates. Behav Brain Res 2009, 201:48-52.

16. Aritake-Okada S, Higuchi S, Suzuki H, Kuriyama K, Enomoto M, Soshi T, Kitamura S, Watanabe M, Hida A, Matsuura M, Uchiyama M, Mishima K. Diurnal fluctuations in subjective sleep time in humans. Neurosci Res 2010, 68:225-231.

17. Hawkins J: Sleep disturbance in intentional self-awakenings: behaviorgenetic and transient factors. Percept Mot Skills 1989, 69:507-510.

18. Morell V: Setting a biological stopwatch. Science 1996, 271:905-906.

19. Schubotz Rl, Friederici AD, von Cramon DY: Time perception and motor timing: a common cortical and subcortical basis revealed by fMRI. Neuroimage 2000, 11:1-12.

20. Rao SM, Mayer AR, Harrington DL: The evolution of brain activation during temporal processing. Nat Neurosci 2001, 4:317-323.

21. Harrington DL, Boyd LA, Mayer AR, Sheltraw DM, Lee RR, Huang M, Rao SM: Neural representation of interval encoding and decision making. Brain Res Cogn Brain Res 2004, 21:193-205.

22. Jueptner M, Rijntjes M, Weiller C, Faiss JH, Timmann D, Mueller SP, Diener HC: Localization of a cerebellar timing process using PET. Neurology 1995, 45:1540-1545

23. Spencer RM, Zelaznik HN, Diedrichsen J, Ivry RB: Disrupted timing of discontinuous but not continuous movements by cerebellar lesions. Science 2003, 300:1437-1439.

24. Ivry RB, Spencer RM: The neural representation of time. Curr Opin Neurobiol 2004, 14:225-232.

25. Lalonde $\mathrm{R}$, Hannequin D: The neurobiological basis of time estimation and temporal order. Rev Neurosci 1999, 10:151-173.

26. Meck WH: Frontal cortex lesions eliminate the clock speed effect of dopaminergic drugs on interval timing. Brain Res 2006, 1108:157-167.

27. Meck WH, Penney TB, Pouthas V: Cortico-striatal representation of time in animals and humans. Curr Opin Neurobiol 2008, 18:145-152.
28. Harrington DL, Haaland KY, Knight RT: Cortical networks underlying mechanisms of time perception. J Neurosci 1998, 18:1085-1095.

29. Mangels JA, Ivry RB, Shimizu N: Dissociable contributions of the prefrontal and neocerebellar cortex to time perception. Brain Res Cogn Brain Res 1998, 7:15-39.

30. Maquet P, Lejeune H, Pouthas V, Bonnet M, Casini L, Macar F, Timsit-Berthier M, Vidal F, Ferrara A, Degueldre C, Quaglia L, Delfiore G, Luxen A, Woods R, Mazziotta JC, Comar D: Brain activation induced by estimation of duration: a PET study. Neuroimage 1996, 3:119-126.

31. Shiotsuka S, Atsumi Y, Ogata S, Yamamoto R, Igawa M, Takahashi K, Hirasawa H, Koyama K, Maki A, Yamashita Y, Koizumi H, Toru M: Cerebral blood volume in the sleep measured by near-infrared spectroscopy. Psychiatry Clin Neurosci 1998, 52:172-173.

32. Hoshi $Y$, Onoe H, Watanabe Y, Andersson J, Bergstrom M, Lilja A, Langstrom B, Tamura M: Non-synchronous behavior of neuronal activity, oxidative metabolism and blood supply during mental tasks in man. Neurosci Lett 1994, 172:129-133.

33. Spielman AJ, Zhang G, Yang CM, D'Ambrosio P, Serizawa S, Nagata M, von Gizycki H, Alfano RR: Intracerebral hemodynamics probed by near infrared spectroscopy in the transition between wakefulness and sleep. Brain Res 2000, 866:313-325.

34. Fantini S, Aggarwal P, Chen K, Franceschini MA, Ehrenberg BL: Nearinfrared spectroscopy and polysomnography during all-night sleep in human subjects. Proc SPIE 2003, 5068:155-162.

35. Pierro ML, Sassaroli A, Bergethon PR, Ehrenberg BL, Fantini S: Phaseamplitude investigation of spontaneous low-frequency oscillations of cerebral hemodynamics with near-infrared spectroscopy: a sleep study in human subjects. Neuroimage 2012, 63:1571-1584.

36. Hoshi Y, Mizukami S, Tamura M: Dynamic features of hemodynamic and metabolic changes in the human brain during all-night sleep as revealed by near-infrared spectroscopy. Brain Res 1994, 652:257-262.

37. Hayakawa T, Terashima M, Kayukawa Y, Ohta T, Okada T: Changes in cerebral oxygenation and hemodynamics during obstructive sleep apneas. Chest 1996, 109:916-921.

38. Kusaka T, Kawada K, Okubo K, Nagano K, Namba M, Okada H, Imai T, Isobe $\mathrm{K}$, Itoh S: Noninvasive optical imaging in the visual cortex in young infants. Hum Brain Mapp 2004, 22:122-132.

39. Shinba T, Nagano M, Kariya N, Ogawa K, Shinozaki T, Shimosato S, Hoshi Y: Near-infrared spectroscopy analysis of frontal lobe dysfunction in schizophrenia. Biol Psychiatry 2004, 55:154-164.

40. Schroeter ML, Kupka T, Mildner T, Uludag K, von Cramon DY: Investigating the post-stimulus undershoot of the BOLD signal-a simultaneous fMRI and fNIRS study. Neuroimage 2006, 30:349-358.

41. Koch SP, Werner P, Steinbrink J, Fries P, Obrig H: Stimulus-induced and state-dependent sustained gamma activity is tightly coupled to the hemodynamic response in humans. J Neurosci 2009, 29:13962-13970.

42. Cui X, Bray S, Bryant DM, Glover GH, Reiss AL: A quantitative comparison of NIRS and fMRI across multiple cognitive tasks. Neuroimage 2011, 54:2808-2821.

43. Strangman G, Culver JP, Thompson JH, Boas DA: A quantitative comparison of simultaneous BOLD fMRI and NIRS recordings during functional brain activation. Neuroimage 2002, 17:719-731.

44. Tamura T, Eda H, Takada M, Kubodera T: New instrument for monitoring hemoglobin oxygenation. Adv Exp Med Biol 1989, 248:103-107.

45. Soshi T, Kuriyama K, Aritake S, Enomoto M, Hida A, Tamura M, Kim Y, Mishima K: Sleep deprivation influences diurnal variation of human time perception with prefrontal activity change: a functional near-infrared spectroscopy study. PLoS One 2010, 5:e8395.

46. Wray S, Cope M, Delpy DT, Wyatt JS, Reynolds EOR: Characterization of the near-infrared absorption spectra of cytochrome aa 3 and haemoglobin for the non-invasive monitoring of cerebral oxygenation. Biochim Biophys Acta 1988, 933:184-192.

47. Matcher SL, Elwell CE, Cooper CE, Cope M, Deipy DT: Performance comparison of several published tissue near-infrared spectroscopy algorithms. Anal Biochem 1995, 227:54-68.

48. Laser Institute of America: American National Standards for the Safe Use of Lasers. Orland: American National Standards Institute; 2007.

49. Rechtschaffen A, Kales A: A manual of Standardized Terminology, Techniques and Scoring System for Sleep Stages of Human Subjects. Los Angeles: Brain Information Service/Brain Research Institute, University of California; 1968. 
50. American Sleep Disorders Association: EEG arousals: scoring rules and examples: a preliminary report from the sleep disorders atlas task force of the American sleep disorders association. Sleep 1992, 15:173-184.

51. Hoshi Y, Kobayashi N, Tamura M: Interpretation of near-infrared spectroscopy signals: a study with a newly developed perfused rat brain model. J Appl Physiol 2001, 90:1657-1662.

52. Hall W: The time sense. Br J Psychiatry 1927, 73:421-428.

53. Brush EN: Observations on temporal judgement during sleep. Am J Psycho 1930, 42:408-441.

54. Hono $T$, Hiroshige $Y$, Miyata $Y$ : Nocturnal sleep at a predetermined time in health undergraduate student. Kawasaki Med J 1991, 1:209-215.

55. Kubota Y, Takasu NN, Horita S, Kondo M, Shimizu M, Okada T, Wakamura T, Toichi M: Dorsolateral prefrontal cortical oxygenation during REM sleep in humans. Brain Res 2011, 1389:83-92.

56. Coull JT, Vidal F, Nazarian B, Macar F: Functional anatomy of the attentional modulation of time estimation. Science 2004, 303:1506-1508.

57. Bonne O, Gilboa A, Louzoun Y, Brandes D, Yona I, Lester H, Barkai G, Freedman N, Chisin R, Shalev AY: Resting regional cerebral perfusion in recent posttraumatic stress disorder. Biol Psychiatry 2003, 54:1077-1086.

58. Ottowitz WE, Dougherty DD, Sirota A, Niaura R, Rauch SL, Brown WA: Neural and endocrine correlates of sadness in women: implications for neural network regulation of HPA activity. J Neuropsychiatry Clin Neurosci 2004, 16:446-455.

59. Wang J, Rao H, Wetmore GS, Furlan PM, Korczykowski M, Dinges DF, Detre JA: Perfusion functional MRI reveals cerebral blood flow pattern under psychological stress. Proc Natl Acad Sci USA 2005, 102:17804-17809.

60. Urry HL, van Reekum CM, Johnstone T, Kalin NH, Thurow ME, Schaefer HS, Jackson CA, Frye CJ, Greischar LL, Alexander AL, Davidson RJ: Amygdala and ventromedial prefrontal cortex are inversely coupled during regulation of negative affect and predict the diurnal pattern of cortisol secretion among older adults. J Neurosci 2006, 26:4415-4425.

61. Edinger JD, Krystal AD: Subtyping primary insomnia: is sleep state misperception a distinct clinical entity? Sleep Med Rev 2003, 7:203-214.

62. American Academy of Sleep Medicine: ICSD-2-International Classification of Sleep Disorders, 2nd ed.: Diagnostic and Coding Manual. Rochester: American Academy of Sleep Medicine; 2005.

63. Fernandez-Mendoza J, Calhoun SL, Bixler EO, Karataraki M, Liao D, VelaBueno A, Jose Ramos-Platon M, Sauder KA, Basta M, Vgontzas AN: Sleep misperception and chronic insomnia in the general population: role of objective sleep duration and psychological profiles. Psychosom Med 2011, 73:88-97.

doi:10.1186/1471-2202-13-153

Cite this article as: Aritake et al:: Increased cerebral blood flow in the right frontal lobe area during sleep precedes self-awakening in humans. BMC Neuroscience 2012 13:153.

\section{Submit your next manuscript to BioMed Central and take full advantage of:}

- Convenient online submission

- Thorough peer review

- No space constraints or color figure charges

- Immediate publication on acceptance

- Inclusion in PubMed, CAS, Scopus and Google Scholar

- Research which is freely available for redistribution 